\title{
Comparison of fully quantitative and semi- quantitative measure of women's myocardial perfusion reserve for detection of microvascular coronary dysfunction
}

\author{
David Chen ${ }^{1,2^{*}}$, Behzad Sharif ${ }^{1}$, Afsaneh Haftbaradaran ${ }^{1}$, Melody Zaya ${ }^{1}$, Chrisandra Shufelt ${ }^{1}$, Puja K Mehta ${ }^{1}$, \\ Daniel S Berman', Louise E Thomson', Debiao Li', Noel Bairey Merz'
}

From 16th Annual SCMR Scientific Sessions

San Francisco, CA, USA. 31 January - 3 February 2013

\section{Background}

Myocardial perfusion reserve (MPR) acquired using firstpass cardiac MRI is a measure of the severity of microvascular coronary dysfunction (MCD) in subjects with signs and symptoms of ischemia but no obstructive coronary artery disease (CAD) [Shufelt 2011]. Semiquantitative measures (upslopes) have been used to analyze MPR data in the previous work [Shufelt 2011]. In this work, we propose using a fully quantitative myocardial blood flow (MBF) analysis to evaluate whether MPR is different between subjects with MCD and normal controls.

\section{Methods}

Control $(n=9)$ and MCD subjects $(n=10)$ from the Women's Ischemia Syndrome Evaluation Coronary Vascular Dysfunction (WISE CVD) multi-center National Heart, Lung, and Blood sponsored study underwent cardiac perfusion MRI studies on a Siemens 1.5T Avanto system with IRB approval and written consent. Control subjects were middle aged women with no risk factors and normal exercise ECG. Diseased subjects were middle aged women presenting with signs and symptoms of ischemia but no obstructive CAD ( $<50 \%$ stenosis) on angiography. A standardized first pass adenosine stress and rest first pass perfusion protocol with breath hold was performed. Segmentation (AHA) and upslope analysis were performed using CAAS MRV (PIE Medical Imaging).
Only the midslice segments were analyzed to insure minimize effect of cardiac phase related MBF variations [Radjenovic 2010]. Signal intensity curves used for MBF estimation was found using the same segments and exported using CAAS MRV. MBFs were found using nonparametric deconvolution code written in MATLAB [Jerosh-Herold 2002]. A two sided Student's t-test was performed to compare groups.

\section{Results}

Mean MPR for diseased and normal populations averaged across all AHA segments in the midslice are summarized in table 1 . There is a significant difference in MPR between normal and diseased groupds using the fully quantitative MBF analysis compared to a trend using for the semi-quantitative upslope analysis.

\section{Conclusions}

MPR measured by quantitative MBF analysis provides better detection of MCD than that using semi-quantitative upslopes. This finding could be explained by the observation that upslopes may not be sensitive to high blood flows [Hsu 2006], which potentially reduces the difference between diseased (ischemic) and normal tissues. In conclusion, fully quantitative MBF analysis improves detection of MCD over semi-quantitative measures. Additional work in more subjects, as well as validation with MPR measured by PET is needed.

'BIRI, Cedars Sinai Hospital, Los Angeles, CA, USA

Full list of author information is available at the end of the article

C 2013 Chen et al; licensee BioMed Central Ltd. This is an Open Access article distributed under the terms of the Creative Commons 
Table 1

\begin{tabular}{cccc}
\hline & Control & Abnormal, no CAD & p-value \\
\hline Fully Quantitative (MBF) & $2.91 \pm 0.37$ & $2.28 \pm 0.58$ & 0.014 \\
Semi-Quantitative (Upslope) & $2.02 \pm 0.63$ & $1.59 \pm 0.40$ & 0.085 \\
\hline
\end{tabular}

Mean MPR found using MBF estimation and upslopes in control and abnormal populations. MBF parameter yielded significant difference between normal and abnormal population while upslopes did not.

\section{Funding}

T32 EB51705; RO1 EB002623; AHA 11POST7390063; N01-HV-68161; N01-HV-68162; N01-HV-68163; N01HV-68164; U0164829; U01 HL649141; U01 HL649241; T32HL69751; 5R01HL090957; 1R03AG032631.

\section{Author details}

${ }^{1} \mathrm{BIRI}$, Cedars Sinai Hospital, Los Angeles, CA, USA. ${ }^{2}$ Northwestern University, Evanston, IL, USA.

Published: 30 January 2013

doi:10.1186/1532-429X-15-S1-P75

Cite this article as: Chen et al:: Comparison of fully quantitative and semi-quantitative measure of women's myocardial perfusion reserve for detection of microvascular coronary dysfunction. Journal of Cardiovascular Magnetic Resonance 2013 15(Suppl 1):P75.

Submit your next manuscript to BioMed Central and take full advantage of:

- Convenient online submission

- Thorough peer review

- No space constraints or color figure charges

- Immediate publication on acceptance

- Inclusion in PubMed, CAS, Scopus and Google Scholar

- Research which is freely available for redistribution

Submit your manuscript at www.biomedcentral.com/submit 